\title{
Identification of chemical compounds from the leaves of Leea indica
}

\author{
GOVINDARAJAPURAM VARADARAJAN \\ SRINIVASAN \\ CHOORIKKAT RANJITH \\ KOCHUKARATU KRISHNAN VIJAYAN* \\ Organic Chemistry Research Laboratory \\ Department of Chemistry \\ University of Calicut \\ Kerala-673 635, India
}

Accepted March 6, 2008
Twenty-three known chemical compounds were identified in the leaves of Leea indica (Burm. f.) Merr. (Leeaceae) by GC-MS analysis, spectroscopic techniques and co-TLC with authentic samples. The identified compounds include eleven hydrocarbons, phthalic acid, palmitic acid, 1-eicosanol, solanesol, farnesol, three phthalic acid esters, gallic acid, lupeol, $\beta$-sitosterol and ursolic acid. Gallic acid was isolated as $n$-butyl gallate and identified by co-TLC. This seems to be the first report of the presence of gallic acid in the leaves of L. indica.

Keywords: Leea indica (Leeaceae), GC-MS, gallic acid, n-butyl gallate, antioxidant activity

Leea indica (L. indica) is widely spread in the forests of tropical and subtropical India. It is a perennial shrub with stout, soft wooded, glabrous stems. Its leaves and roots are reportedly of medicinal value. The leaves are useful for the treatment of diabetes and the ointment prepared from roasted leaves relieves vertigo $(1,2)$. Its root is used as a sudorific, antidiarrhoeal, antidysenteric, antispasmodic and to treat cardiac and skin diseases (1). The whole plant is used traditionally for headache, body pains and skin complaints $(3,4)$.

A number of compounds have been reported from plants belonging to the genus Leea. The methanolic extract of L. indica was reported to possess strong antioxidant activity (5). A new megastigmane diglycoside, leeaoside, was isolated along with four known compounds: benzyl-O- $\alpha$-L-rhamnopyranosyl- $(1 \rightarrow 6)-\beta$-D-glucopyranoside, quercetin-3-O- $\alpha$-L-rhamnopyranoside, myricetin-3-O- $\alpha$-L-rhamnopyranoside and citroside A from the leaves of L. thorelli (6). Quercitrin-3'-sulphate (7) and antioxidant flavonoids and phenolics (8) were isolated from the leaves of L. guinensis. Sixty-nine compounds were identified by GC-MS analysis of essential oil from the leaves and wood of L. guinensis (9). The aqueous extract of the leaves of L. guinensis has been reported to possess anti-edematogenic activity (10). The chemical composition of essential oil from the leaves of L. longifolia Merr. has been established (11). The crude methanolic extracts of the leaves, stem and root bark of L. tetramera were reported to possess antibacterial activity (12).

*Correspondence, e-mail: prof.kkvijayan@yahoo.co.in 
Since there are no reports on the phytochemical aspects of L. indica, it was chosen for the present study. It has been reported that methanol extract of L. indica showed antioxidant and nitric oxide inhibitory activities (5).

\section{EXPERIMENTAL}

\section{Plant material}

The leaves of L. indica were collected from the Calicut University Campus, South India, in March 2005 and were authenticated by Dr. A. K. Pradeep, Department of Botany, University of Calicut, India. A voucher specimen No. 106601(CALI) has been deposited in the Herbarium of this University. The shade-dried and coarsely powdered leaves were used for the phytochemical investigation.

\section{Materials and methods}

All the solvents used were of guaranteed reagent quality (Merck, India). Precoated silica gel $60 \mathrm{~F}_{254}$ plates of $0.2 \mathrm{~mm}$ thickness (Merck, Germany) were used for TLC. The spots were visualized by spraying with anisaldehyde-sulphuric acid (AS) reagent, followed by heating at $110{ }^{\circ} \mathrm{C}$ for $5 \mathrm{~min}$ and also by using $10 \% \mathrm{MeOH} / \mathrm{FeCl}_{3}$ reagent. Standard samples were purchased from Sigma Aldrich (USA).

UV spectra were recorded on a Shimadzu UV-1700 model (Japan) double beam spectrophotometer and IR spectra on a Perkin-Elmer 377 spectrometer (USA) as KBr pellets. ${ }^{1} \mathrm{H}$ and ${ }^{13} \mathrm{C}$ NMR spectra were recorded in DMSO- $d_{6}$ at 300 and $75 \mathrm{MHz}$, respectively, on a Bruker Spectrospin NMR instrument (Germany) using TMS as internal standard. EI-MS spectrum was scanned at $70 \mathrm{eV}$ on a JEOL JMS600 instrument (Japan) and FAB-MS on a JEOL JMS600 instrument using 3-nitrobenzyl alcohol as matrix. CHN analysis was conducted using a VarioEL III CHNS instrument (Germany).

GC-MS analysis was performed by splitless injection of $1.0 \mu \mathrm{L}$ of the sample in hexane on a Hewlett Packard 6890 (USA) gas chromatograph fitted with a cross-linked 5\% phenyl methyl siloxane HP-5 MS capillary column $(30 \mathrm{~m} \times 0.32 \mathrm{~mm} \times 0.25 \mu \mathrm{m}$ coating thickness), coupled with a model 5973 mass detector. GC-MS operating conditions were as follows: injector temperature $220^{\circ} \mathrm{C}$, transfer line $290{ }^{\circ} \mathrm{C}$, oven temperature programme $60-290{ }^{\circ} \mathrm{C}$ with ramping $5^{\circ} \mathrm{C} \mathrm{min}^{-1}$, carrier gas: helium at $1.5 \mathrm{~mL} \mathrm{~min}-1$, mass spectra: electron impact $\left(\mathrm{EI}^{+}\right)$, ion source temperature: $250{ }^{\circ} \mathrm{C}$. Individual components were identified by Wiley 275.L database matching.

\section{Extraction}

Powdered material $(2.7 \mathrm{~kg})$ was extracted with methanol $(5 \times 3 \mathrm{~L})$ in a Soxhlet apparatus for $12 \mathrm{~h}$. The combined extract was concentrated to $700 \mathrm{~mL}$ in a Büchi type rotavapor (India) at $60{ }^{\circ} \mathrm{C}$. It was then fractionated using petroleum ether $\left(60-80^{\circ} \mathrm{C}\right)$ and 1 butanol. 


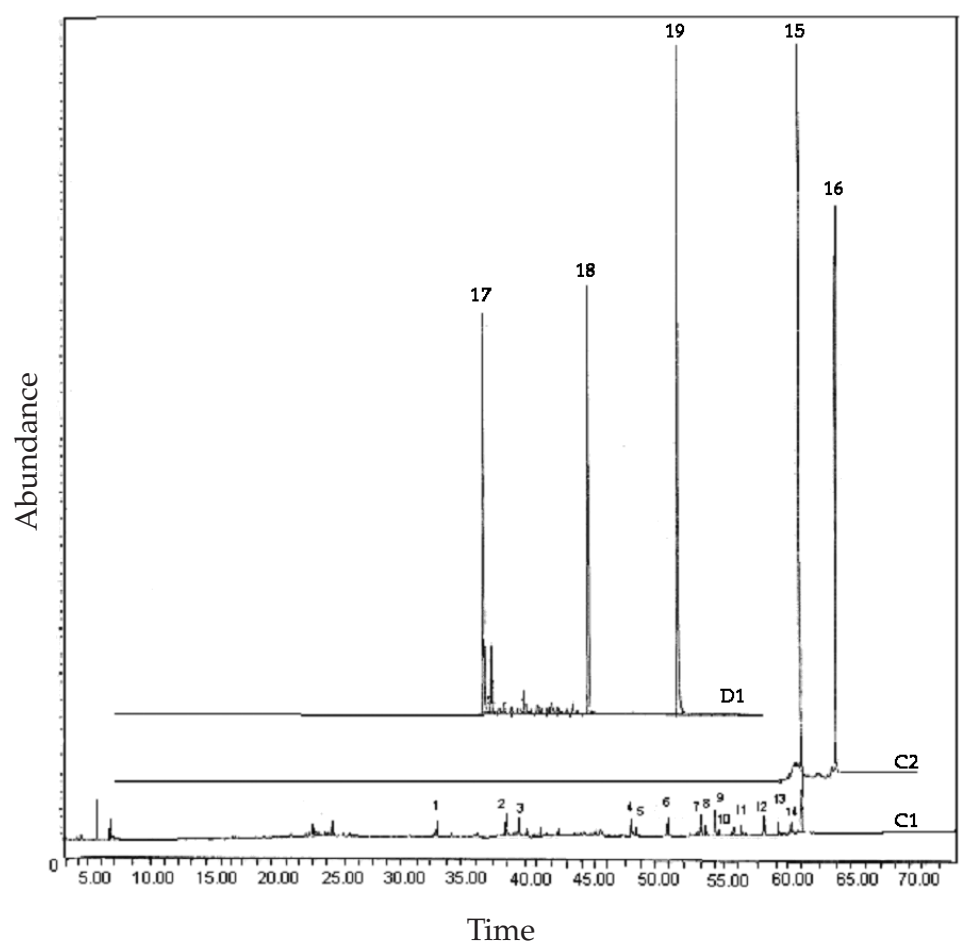

Fig. 1. GC chromatogram of $C_{1}, C_{2}$ and $D_{1}$.

\section{Identification of compounds present in the petroleum ether (PE) fraction}

The PE fraction $(2.5 \mathrm{~L})$ was concentrated under reduced pressure to obtain $20 \mathrm{~g}$ of the residue. The residue was subjected to column chromatography using silica gel (60-120 mesh) as adsorbent. Stepwise elution was carried out with $\mathrm{PE}, \mathrm{PE}-\mathrm{CHCl}_{3}$ and $\mathrm{PE}-\mathrm{CHCl}_{3}$-ethyl acetate mixtures in different proportions. When eluted with $\mathrm{PE}-\mathrm{CHCl}_{3}$ (10:1), a yellow solid $\mathrm{C}_{1}(0.17 \mathrm{~g})$ was obtained. Further elution with $\mathrm{PE}-\mathrm{CHCl}_{3}$-ethyl acetate (20:4:1) yielded $C_{2}$ as a colourless waxy solid (0.12 g). The compounds present in $C_{1}$ and $\mathrm{C}_{2}$ were identified by GC-MS analysis. The relative percentage of compounds was calculated from the peak area (Table I).

\section{Identification of compounds present in 1-butanol fraction}

After fractionation with PE, the residual methanol extract (85 g) was shaken with $2 \mathrm{~mol} \mathrm{~L}^{-1} \mathrm{HCl}$ and 1-butanol (1:10) for $5 \mathrm{~min}$ to obtain the 1-butanol fraction, which was concentrated under reduced pressure to get $30 \mathrm{~g}$ of a reddish brown mass. A column chromatographic separation of this residue was done on a silica gel (60-120 mesh) column using $\mathrm{CHCl}_{3}$ and $\mathrm{CHCl}_{3}$-acetone mixture as the eluent. The fraction collected by elution with $\mathrm{CHCl}_{3}$ alone afforded a reddish brown liquid $\mathrm{D}_{1}(0.08 \mathrm{~g})$ and 5:2 $\mathrm{CHCl}_{3}$-ac- 
Table I. Chemical composition of $C_{1}, C_{2}$ and $D_{1}$

\begin{tabular}{|c|c|c|c|c|}
\hline Fraction & Peak ID & Compound identified & $t_{\mathrm{R}}(\min )$ & Concentration (\%) \\
\hline \multirow{16}{*}{$\mathrm{C}_{1}$} & 1 & n-Octadecane & 32.44 & 0.61 \\
\hline & 2 & Palmitic acid & 37.94 & 0.68 \\
\hline & 3 & $n$-Eicosane & 38.96 & 0.64 \\
\hline & 4 & $n$-Tricosane & 47.71 & 0.89 \\
\hline & 5 & Farnesol & 47.81 & 0.39 \\
\hline & 6 & $n$-Tetracosane & 50.40 & 1.06 \\
\hline & 7 & $n$-Tetratetracontane & 52.98 & 1.49 \\
\hline & 8 & Solanesol & 53.43 & 0.48 \\
\hline & 9 & Phthalic acid & 54.12 & 3.42 \\
\hline & 10 & 17-Pentatriacontene & 55.36 & 0.35 \\
\hline & 11 & $n$-Heptacosane & 55.47 & 1.45 \\
\hline & 12 & $n$-Tetratriacontane & 57.87 & 2.03 \\
\hline & 13 & 1-Eicosanol & 60.11 & 1.03 \\
\hline & 14 & $n$-Tritetracontane & 60.22 & 1.75 \\
\hline & 15 & Lycopersen & 60.84 & 74.38 \\
\hline & & Total & & 90.65 \\
\hline $\mathrm{C}_{2}$ & 16 & $n$-Heptadecane & 61.16 & 97.88 \\
\hline \multirow{4}{*}{$\mathrm{D}_{1}$} & 17 & di- $n$-Butyl phthalate & 37.74 & 21.99 \\
\hline & 18 & Butyl-2-ethylhexyl phthalate & 46.61 & 22.90 \\
\hline & 19 & Isooctyl phthalate & 54.18 & 40.69 \\
\hline & & Total & & 84.88 \\
\hline
\end{tabular}

$t_{\mathrm{R}}$ - retention time

etone mixture yielded $\mathrm{D}_{2}$ as a pure solid, which was further recrystallized from hot methanol to obtain reddish brown crystals having m.p. at $120-123{ }^{\circ} \mathrm{C}(0.15 \mathrm{~g})$. $\mathrm{D}_{1}$ was subjected to GC-MS analysis and the results obtained are summarized in Table I.

\section{Identification of $\beta$-sitosterol, lupeol, ursolic acid and gallic acid by} co-TLC with standards

A co-TLC analysis was carried out with $80 \%$ methanol extract of the leaves on a precoated silica gel $60 \mathrm{~F}_{254}$ plate. For this analysis, $10 \mu \mathrm{L}$ of the extract and standard solutions were applied on the precoated plate $(5 \times 10 \mathrm{~cm})$ and developed to a distance of $8 \mathrm{~cm}$. Lupeol, $\beta$-sitosterol and ursolic acid in the methanol extract were identified by co-TLC against standard samples using a PE-ethyl acetate (4:1) solvent system. The presence of gallic acid in the methanol extract was also identified by spotting against the standard sample using a 30:30:9:1.25 toluene-ethyl acetate (EA)-formic acid (FA)-methanol solvent system. 


\section{RESULTS AND DISCUSSION}

The PE extract of the L. indica leaves yielded in column chromatography two fractions, $\mathrm{C}_{1}$ and $\mathrm{C}_{2}$. The compounds present herein were identified by GC-MS analysis (Fig. 1). Fifteen compounds were identified in fraction $C_{1}(90.65 \%)$. The prevailing compound in $C_{1}$ was lycopersen $(74.38 \%)$, a long-chain unsaturated hydrocarbon. The other identified compounds include $n$-octadecane, $n$-eicosane, $n$-tricosane, $n$-tetracosane, $n$-tetratetracontane, 17 -pentatriacontene, $n$-heptacosane, $n$-tetratriacontane, $n$-tritetracontane, phthalic acid, palmitic acid, 1-eicosanol, solanesol and farnesol. $n$-Heptadecane was identified by GC-MS analysis as the main constituent $(97.88 \%)$ of fraction $\mathrm{C}_{2}$.

The butanol extract of the leaves yielded in column chromatography two fractions, $\mathrm{D}_{1}$ and $\mathrm{D}_{2} . \mathrm{D}_{1}$ was obtained as a reddish brown liquid in which the compounds di- $n$-butyl phthalate, butyl-2-ethylhexyl phthalate and isooctyl phthalate were identified by GC-MS analysis $\left(84.88 \%\right.$ ) (Fig. 1). From fraction $\mathrm{D}_{2}$, a pure reddish brown solid was obtained which was identified as $n$-butyl gallate $\left(\mathrm{C}_{11} \mathrm{H}_{14} \mathrm{O}_{5}, 226.22\right)$ from the spectral data. The structure of $n$-butyl gallate is shown in Fig. 2 along with the $\delta$ values of the ${ }^{1} \mathrm{H}$ and ${ }^{13} \mathrm{C}$ nuclei.

UV, IR, ${ }^{1} \mathrm{H}$ NMR, ${ }^{13} \mathrm{C}$ NMR and mass spectrometry data of $\mathrm{D}_{2}$ are as follows: UV ( $\left.\lambda_{\max } \mathrm{nm}, \mathrm{CH}_{3} \mathrm{OH}\right): 221.51,276.47$; IR $\left(v \mathrm{~cm}^{-1}\right): 3493,3329$ (OH str.), 2962 (CH str.), 1687 (C=O str.); ${ }^{1} \mathrm{H}$ NMR $(\delta$ ppm, $300 \mathrm{MHz}): 0.92\left(\mathrm{t}, J=7.5 \mathrm{~Hz}, 3 \mathrm{H}, \mathrm{CH}_{3}\right), 1.43$ (sextet, $J=7.2$ and $\left.7.5 \mathrm{~Hz}, 2 \mathrm{H}, \mathrm{CH}_{2}\right), 1.58$ (quintet, $J=6.3$ and $\left.7.8 \mathrm{~Hz}, 2 \mathrm{H}, \mathrm{CH}_{2}\right), 4.15(\mathrm{t}, J=6.0 \mathrm{~Hz}, 2 \mathrm{H}$, $\left.\mathrm{CH}_{2}\right), 6.90(\mathrm{~s}, 2 \mathrm{H}, \mathrm{ArH}), 8.90(\mathrm{~s}, 1 \mathrm{H}, \mathrm{OH}), 9.25(\mathrm{~s}, 2 \mathrm{H}, \mathrm{OH}) ;{ }^{13} \mathrm{C} \mathrm{NMR}(\delta \mathrm{ppm}, 75 \mathrm{MHz})$ : $13.55,18.77,30.34,63.55,108.45,120.59,137.21,144.43,166.80$; EIMS: $m / z 226\left(\mathrm{M}^{+}, 100 \%\right)$, 211, 209, 181, 133, 75; FABMS: $m / z 227(\mathrm{M}+1), 171(100 \%), 153,149,138,125,102,89,79$, 57. Elemental analysis: found (\%): $\mathrm{C}, 57.99 ; \mathrm{H}, 7.01 ; \mathrm{O}, 35$ (calcd. for $\mathrm{C}_{11} \mathrm{H}_{14} \mathrm{O}_{5}$ : $\mathrm{C}, 58.41$; H, 6.19).

During ${ }^{1} \mathrm{H}$ NMR analysis, peaks at $\delta 8.90$ and 9.25 ppm disappeared by the addition of $\mathrm{D}_{2} \mathrm{O}$, which clearly indicates that both protons belong to the $\mathrm{OH}$ group.

Preliminary phytochemical screening of the $80 \%$ methanol extract of the leaves revealed the presence of some triterpenes and steroids. To identify these compounds, co-TLC was carried out with a number of standards. Thus, two triterpenes, lupeol $\left(R_{\mathrm{F}}=\right.$ $0.85)$ and ursolic acid $\left(R_{\mathrm{F}}=0.28\right)$, and one sterol, $\beta$-sitosterol $\left(R_{\mathrm{F}}=0.58\right)$, were identified from the methanol extract by co-TLC against authentic samples (Fig. 3).

Fig. 2. Structure of: a) $n$-butyl gallate and b) gallic acid. a)



b)<smiles>O=C(O)c1cc(O)c(O)c(O)c1</smiles> 
a)

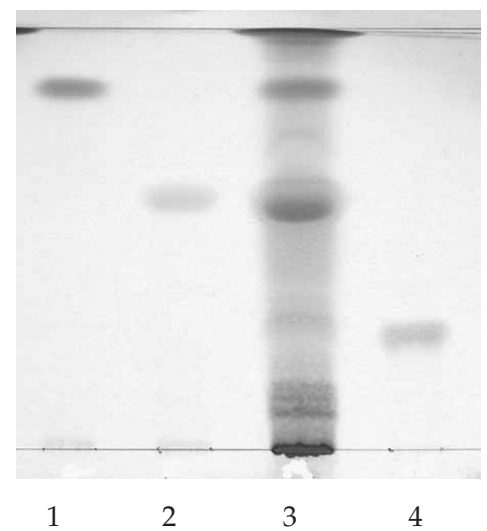

Track: 1-Std. lupeol Track: 2-Std. b-sitosterol Track: 3-MeOH extract Track: 4-Std. ursolic acid

Solvent system: 4:1 PE-EA Visualization: AS reagent in Vis. b)

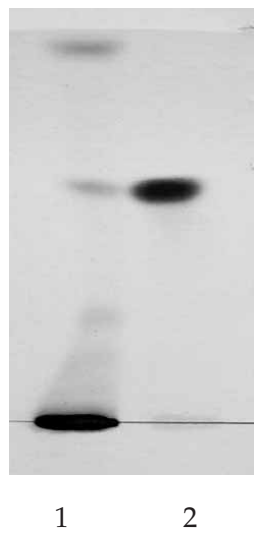

Track: 1-MeOH extract Track: 2-Std. gallic acid

Solvent system: 30:30:9:1.25

Toluene-EA-FA-MeOH

Visualization: $10 \% \mathrm{MeOH} / \mathrm{FeCl}_{3}$

Fig. 3. Co-TLC of MeOH extract with: a) lupeol, $\beta$-sitosterol and ursolic acid; b) with gallic acid.

The presence of gallic acid $\left(R_{\mathrm{F}}=0.49\right)($ Fig. $2 \mathrm{~b})$ in the leaves of L. indica was unambiguously confirmed by co-TLC against an authentic sample (Fig. 3b). Acidification of the methanol extract led to a precipitate of gallic acid, witch dissolved in butanol. This gallic acid got esterified into butyl gallate under hot conditions while concentrating the butanol extract. The butyl gallate was isolated using a silica gel column and was identified by spectroscopic techniques. For confirmation, the methanolic extract was subjected to co-TLC with isolated butyl gallate and a standard of gallic acid using a toluene/ethyl acetate/formic acid/methanol (30:30:9:1.25) solvent system. After spraying the TLC plate with a $10 \% \mathrm{MeOH} / \mathrm{FeCl}_{3}$ reagent, only the green spot of gallic acid matched the one present in the extract $\left(R_{\mathrm{F}}=0.49\right)$. There was no corresponding spot in the methanolic extract for $n$-butyl gallate $\left(R_{\mathrm{F}}=0.74\right)$. Hence it can be stated that the leaves of $L$. indica contain gallic acid in the free state and not as butyl ester.

\section{CONCLUSIONS}

The present investigation has helped identify the compounds present in the leaves of Leea indica, a hitherto uninvestigated species. The presence of a large number of long-chain hydrocarbons is common in the leaves of tropical plants, which to some extent lower the rate of transpiration. It can be concluded from our results that the strong anti- 
oxidant activity reported for the leaves of L. indica is mainly due to the presence of gallic acid, a well known antioxidant compound.

Acknowledgement. - The authors thank the Director (Laboratories), Textile Committee, Ministry of Textiles, Government of India, for providing GC-MS analyses.

\section{REFERENCES}

1. A. Chatterjee and S. C. Prakashi, Vol. III, The Treatise on Indian Medicinal Plants, NISCAIR, New Delhi 1994, pp. 173-174.

2. N. D. Prajapati, S. S. Purohit, A. K. Sharma and T. Kumar, A Handbook of Medicinal Plants $-A$ Complete Source Book, Agrobios (I), Jodhpur 2003, pp. 309-310.

3. I. H. Burkill, A Dictionary of the Economic Products of the Malay Peninsula, Crown Agents, London 1966.

4. A. G. Lattif, I. M. Omar, I. M. Said and A. Kadri, A multi-variate approach to the study of medicinal plants in Malaysia, J. Singapore Natl. Academy Sci. 13 (1984) 101-105.

5. K. Saha, N. H. Lajis, D. A. Israf, A. S. Hamzah, S. Khozirah, S. Khamis and A. Syahida, Evaluation of antioxidant and nitric oxide inhibitory activities of selected Malaysian medicinal plants, J. Ethnopharmacol. 92 (2004) 263-267; DOI: 10.1016/j.jep.2004.03.007.

6. W. Kaewkrud, H. Otsuka, S. Ruchirawat and T. Kanchanapoom, Leeaoside, a new megastigmane diglycoside from the leaves of Leea thorelli Gagnep, J. Nat. Med. 61 (2007) 449-451; DOI: 10.1007/s11418-007-0170-7.

7. P. O. de Beck, M. G. Dijoux, G. Cartier and A. M. Mariotte, Quercitrin-3'-sulphate from leaves of Leea guinensis, Phytochemistry 47 (1998) 1171-1173; DOI: 10.1016/s0031-9422(98)80097-6.

8. P. O. de Beck, G. Cartier, B. David, M. G. Dijoux and A. M. Mariotte, Antioxidant flavonoids and phenolic acids from leaves of Leea guinensis G. Don (Leeaceae), Phytother. Res. 17 (2003) 345347; DOI: 10.1002/ptr.1141.

9. P. O. de Beck, J. M. Bessiere, M. G. D. Franca, B. David and A. M. Mariotte, Volatile constituents from leaves and wood of Leea guinensis G. Don (Leeaceae) from Cameroon, Flavour Frag. J. 15 (2000) 182-185; DOI: 10.1002/1099-1026(200005/06)15:3<182::AID-FFJ888>3.0.CO;2-X.

10. A. Falodun, L. O. Okunrobo and L. O. Agbo, Evaluation of the anti-edematogenic activity of the aqueous extract of Leea guinensis, Afr. J. Biotechnol. 6 (2007) 1151-1153.

11. H. P. Bi, C. R. Han, Z. Y. Liang and S. C. Yang, Chemical constituents of essential oil from leaves of Leea longifolia Merr., J. Plant Resour. Environ. 15 (2006) 72-73.

12. M. R. Khan, A. D. Omoloso and M. Kihara, Antibacterial activity of Alstonia scholaris and Leea tetramera, Fitoterapia 74 (2003) 736-740; DOI: 10.1016/s0367-326x(03)00192-8.

\section{$S A Z \check{E} T A K$}

\section{Identifikacija kemijskih spojeva u listovima biljke Leea indica}

GOVINDARAJAPURAM VARADARAJAN SRINIVASAN, CHOORIKKAT RANJITH i KOCHUKARATU KRISHNAN VIJAYAN*

U listovima biljke Leea indica (Burm. f.) Merr. (Leeaceae) identificirano je 23 sastojka koristeći GC-MS analizu, spektroskopske metode i TLC. Među identificiranim spojevi- 
ma su 11 ugljikovodika, ftalna i palmitinska kiselina, 1-eikozanol, solanesol, farnesol, tri estera ftalne kiseline, galna kiselina, lupeol, $\beta$-sitosterol i urson. Galna kiselina je izolirana kao $n$-butil-galat i identificirana pomoću TLC. Čini se da je ovo prvo izvješće o prisutnosti galne kiseline $\mathrm{u}$ listovima L. indica.

Ključne riječi: Leea indica (Leeaceae), GC-MS, galna kiselina, $n$-butil-galat, antioksidativno djelovanje

Organic Chemistry Research Laboratory, Department of Chemistry, University of Calicut Kerala-673 635, India 